\title{
Flavonol-enriched fraction from Vaccinium macrocarpon fruit inhibits matrix metalloproteinase-2, matrix metalloproteinase-9 and urokinase-type plasminogen activator expression in human prostate cancer cells in vitro
}

\author{
James MacPhee ${ }^{1}$, Colin R. Stetson ${ }^{1,4}$, Benjamin W. Elwood ${ }^{2}$, Kunal Patel ${ }^{3}$, Jason \\ McCallum $^{4}$, Catherine Neto ${ }^{3}$, Robert A.R. Hurta ${ }^{1}$
}

${ }^{1}$ Department of Biology, University of Prince Edward Island, ${ }^{2}$ Department of Veterinary Biomedical Sciences, University of Saskatchewan, ${ }^{3}$ Department of Chemistry and Biochemistry, University of Massachusetts-Dartmouth, ${ }^{4}$ Agriculture and Agri-Food Canada

Submission date: August 29, 2014; Acceptance date: November 14, 2014; Publication date:

November 15, 2014

Corresponding author: Robert Hurta, PhD, Department of Biology, University of Prince Edward Island, 550 University Avenue, Charlottetown, PE, C1A 4P3, Canada

\begin{abstract}
:
Background: Prostate cancer, amongst other cancer types has a genetic and environmental component, which can contribute to prostate cancer development and progression. Vaccinum macrocarpon (American cranberry) is a botanical that contains several phytochemicals which have been suggested to play a role in preventing cardiovascular disease, cancer, and urinary tract infections as well as in the maintenance of oral health.
\end{abstract}

Context and purpose of this study: This investigation evaluated the effects of a flavonolenriched fraction (FL) from the American cranberry (Vaccinium macrocarpon) containing quercetin and myricetin glycosides on matrix metalloproteinase (MMP) and urokinase-type plasminogen activator (uPA) activities and their associated regulatory proteins in DU145 human prostate cancer cells in vitro.

Results: A flavonol-enriched fraction (FL) was prepared from Vaccinium macrocarpon berries and the effect of this fraction on prostate cancer cell behaviour was assessed using biochemical and molecular approaches including cytotoxicity assays and Western blot analysis to determine protein expression. Cranberry FL decreased cellular viability of DU145 cells at a concentration of $25 \mathrm{ug} / \mathrm{ml}$ by $20 \%$ after 6 hours of treatment. Further investigations determined that associated with this cytotoxicity, cranberry FL decreases matrix metalloproteinase (MMP) ( specifically MMP-2 and MMP-9) activity and urokinase plasminogen activator (uPA) activity through effects on specific temporal MMP regulators and UPA regulators and by affecting either the phosphorylation status and/or expression of specific MAP kinase, PI-3 kinase, NF-kB and AP-1 pathway associated proteins. 
Conclusion: This study demonstrates, for the first time, the ability of Vaccinium macrocarpon flavonols to modulate cellular pathways associated with migration, invasion, and proliferation, suggesting that cranberry (Vaccinium macrocarpon) is a viable candidate for further research as a natural product that may protect against certain cancers.

Key Words: Vaccinium macrocarpon, matrix metalloproteinases, urokinase, anti-cancer activity

\section{INTRODUCTION}

Prostate cancer is one of the most common forms of cancer affecting North American men. Metastasis of prostate cancer cells is associated with the invasion of the prostate cancer cells into vasculature thereby providing an opportunity for such cells to disseminate. A family of proteins called the matrix metalloproteinases (MMPs) allows cancerous cells to do just that [1]. MMPs degrade the surrounding extracellular matrix and permit the cancer to access lymph tissue and vasculature. The gelatinases, specifically MMP 2 and MMP 9, degrade gelatin found in the basement membrane of tissues. The expression of these gelatinases has been reported to be up regulated in a variety of different cancerous cells [2,3], a possible reason why these cancers are able to spread throughout the body [4].

Other proteins can play critical roles in affecting this behaviour of cancer cells including prostate cancer cells. Of these, the urokinase-type plasminogen activator (uPA) (herein referred to as urokinase) system may also contribute to the metastatic potential of cancer cells. In this regard, uPA/uPAR signalling system can affect extracellular matrix proteolysis and tumour invasion [5]. This uPA system is an activation cascade for the MMP pathway via plasmin, as well as a direct modifier of extracellular matrix (ECM) via the same protein [6,7]. Activated uPA is capable of facilitating the conversion of plasminogen to plasmin, which then has the capacity to activate the MMPs, and /or degrading the ECM directly [6-8] uPA can affect nuclear localization of c-fos and c-jun which are important to cell growth [5]. Additionally, there is a significant positive correlation between the expression of uPA and the expression of various MMPs [6].

Diet may have an impact and influence on prostate cancer. Some fruits and vegetable have been associated with a decreased risk of developing cancer $[9,10]$. These fruits and vegetables contain many bioactive compounds, which both in vitro and in vivo have profound effects on the behaviour of cancerous cells. Some of these effects include increasing rates of apoptosis, decreasing incidences of metastasis, and arresting the cell cycle [12-15]. Recent reports suggest that cranberry may have additional benefits to the lower urinary tract and could also provide protection against benign prostatic hyperplasia [16].

Previously, we described the effects of a whole cranberry extract containing a variety of flavonoids as well as the effects of a proanthocyanidin enriched fraction isolated from cranberry fruit on matrix metalloproteinaseB2 /- 9 activities in DU145 human prostate adenocarcinoma cells in vitro $[17,18]$. The purpose of the present study is to examine the effect of a flavonol enriched fraction from Vaccinium macrocarpon cranberry fruit on MMPs and uPA and their associated regulatory proteins and associated signalling pathways in DU145 human prostate cancer cells in vitro. This study may shed some light on potential mechanisms of the 
preventative action by these particular compounds, which include quercetin and myrecitin glycosides, in prostate cancer cells and underscore the contribution to the overall health promoting properties of cranberry, a commonly used food and botanical.

\section{MATERIALS AND METHODS}

All antibodies used in this study were purchased from Santa Cruz Biotechnology, Inc. (Santa Cruz, CA). The following antibodies: anti-TIMP-1, anti-TIMP-2, anti-EMMPRIN, anti-actin, anti-Akt 1, anti-pJNK, anti-JNK 1, anti-pI9B $\alpha$, anti-histone $\mathrm{H} 2$, polyclonal anti-p38, anti-pp38, anti-pERK1/2, anti-ERK 1, anti-ERK 2, anti-pAkt 1, PI-3- Kinase p110, anti-NF-9B( p65), antiJNK 2 and monoclonal anti-I9B $\alpha$ and PI-3-Kinase p85 $\alpha$, anti-uPA, anti-uPAR, anti-PAI-1, antiPAI-2, respectively, were used. All other chemicals and materials were purchased as indicated.

Preparation of Cranberry Flavonol-Enriched Extract (FL): Cranberry fruit (Vaccinium macrocarpon) was harvested at the State Bog in Wareham, Massachusetts. The fruit was flashfrozen in liquid nitrogen and stored at $-20^{\circ} \mathrm{C}$ until use. For preparation of the whole cranberry extract and polyphenolic extract, $1.04 \mathrm{~kg}$ of fruit was macerated in $300 \mathrm{~mL}$ solvent in a Waring Blender for 5 minutes, then allowed to stand for 30 minutes. The slurry was filtered and the solids blended with several additional $100 \mathrm{~mL}$ portions of solvent until the solids were nearly colorless. An additional extraction with $200 \mathrm{~mL}$ of ethyl acetate was performed; the filtrates were concentrated by rotary evaporation and freeze-dried, then dissolved again in a minimum volume of distilled water and chromatographed on Diaion HP-20 resin $(5.5 \times 30 \mathrm{~cm})$ to remove free sugars. Extracts were allowed to adsorb to the resin for 15 minutes. The column was washed with 2 L distilled water to remove sugars and organic acids, then eluted with $100 \%$ methanol and the elute concentrated in vасио and freeze-dried to yield $7.11 \mathrm{~g}$ de-sugared crude whole cranberry extract.

Isolation and Characterization of the Flavonol Fraction: Fractionation of the whole cranberry extract was by a published procedure [19]. Briefly, $0.508 \mathrm{~g}$ crude extract was dissolved in a minimum volume of distilled water and applied to a Sephadex LH-20 column packed in 70:30 methanol/water ( $3 \times 22 \mathrm{~cm}$ ). The column was eluted with 70/30 methanol /water to yield a number of coloured fractions containing phenolic acids, anthocyanins and flavonol glycosides, then with 70/30 acetone/water to elute oligomeric proanthocyanidins and nonpolar constituents. The third collected methanolic fraction $(30 \mathrm{mg}$ ) which was reddish-yellow contained primarily flavonol glycosides. This fraction constitutes the flavonol-enriched fraction (FL) used in this study. HPLC analysis was performed on a Waters Millennium binary HPLC system with Waters 515 pumps, a 996 photodiode array (PDA) detector, and Millennium ${ }^{32}$ Version 32.0 software. Absorbance was monitored at 210-600 nm, with $280 \mathrm{~nm}$ indicative of proanthocyanidins, 310 $\mathrm{nm}$ of coumaric acid derivatives, $355 \mathrm{~nm}$ of flavonol glycosides and $520 \mathrm{~nm}$ of anthocyanins. The program used gradient elution at a flow rate of $0.6 \mathrm{~mL} / \mathrm{min}$. on a Waters Symmetry C18 column $(3.0 \times 150 \mathrm{~mm}, 5 \mu \mathrm{m})$, where solvent $\mathrm{A}=2 \%$ aqueous acetic acid and solvent $\mathrm{B}=2 \%$ acetic acid in methanol. Program: 0-5 min, linear gradient from 95\% to $75 \% \mathrm{~A} ; 5-25 \mathrm{~min}$, gradient to $65 \% \mathrm{~A} ; 25-35 \mathrm{~min}$, gradient to $60 \% \mathrm{~A} ; 35-50 \mathrm{~min}$, gradient to $5 \% \mathrm{~A}$, holding at $5 \% \mathrm{~A}$ until $55 \mathrm{~min}$; 55-65 min, gradient to $0 \% \mathrm{~A}$. Peaks were identified by comparison to authentic 
standards and previously published data [20,21]. Total flavonols were determined as quercetin3-O-galactoside equivalents using the standard curve method.

Cell Culture and Treatment with Flavonol Enriched Fraction: Human DU145 prostate adenocarcinoma cells (ATCC, Manassas, VA) were cultured on 100mm plastic tissue-culture dishes (Falcon, Mississauga, ON) in alpha MEM (Gibco, Burlington, ON). Supplemented with $10 \%$ fetal bovine serum (FBS) (Sigma, Oakville, ON.) and 1\% antibiotic-antimycotic (Gibco, Burlington, $\mathrm{ON})$. Cells $\left(4 \times 10^{4}\right)$ were cultured on the tissue culture dishes and were initially incubated for 24 hours at $37^{\circ} \mathrm{C}$ in the presence of $5 \% \mathrm{CO}_{2}$. After this 24 hour incubation period, the media was removed and replaced with serum free alpha MEM supplemented with $5 \mathrm{ug} / \mathrm{ml}$ of transferrin (Sigma) and 2.5ug/ml of insulin (Sigma). These plates were again incubated for 24 hours at $37^{\circ} \mathrm{C}$ in the presence of $5 \% \mathrm{CO}_{2}$. After this incubation period, cells were treated with the flavonol enriched fraction (FL) at a final concentration of $25 \mu \mathrm{g} / \mathrm{ml}$ for six hours. FLs were dissolved in dimethyl sulfoxide (DMSO) as the vehicle prior to use. The control cells received only the vehicle After treatment, the media was removed from the cells and stored at $-80<\mathrm{C}$ for further analysis. The cells were then washed with PBS, and were removed by trypsin (Sigma) diluted in phosphate buffered saline (PBS). The cells were re-suspended with alpha MEM supplemented with $10 \% \mathrm{FBS}$ and were centrifuged for 4 minutes at $500 \mathrm{x}$ g. After centrifugation, the cell pellet was re-suspended with PBS and was transferred to a micro centrifuge tube and was centrifuged at $500 \mathrm{x}$ g for 4 minutes. After centrifugation, this cell pellet was then stored at $-80^{\circ} \mathrm{C}$ until analysed further.

Zymography: Zymography, or gelatin-gel electrophoresis, was performed to evaluate matrix metalloproteinase (MMP) activity essentially as previously described [17]. A 100 ul aliquot of the conditioned media was mixed in a 4:1 ratio with sample buffer, which consisted of 10\% SDS and $0.1 \%$ bromophenol blue in $0.3 \mathrm{M}$ TrisBHCl$(\mathrm{pH} 6.8)$ (Sigma). [This aliquot is representative of the MMP Aactivity@ expressed by 400,000 cells per plate.]. Aliquots of each sample were loaded into wells of a 5\% stacking gel and resolved by electrophoresis at a constant current at ambient temperature. The $10 \%$ resolving gel contained $0.1 \%$ gelatin (Sigma) for three hours. Following electrophoresis, the gel was then incubated with a solution containing $2 \%$ Triton 100X (Sigma) and 0.5 M Tris-HCl (Sigma) for one hour. After this first incubation, the gel was then placed in the second solution containing $0.05 \mathrm{M}$ of Tris- $\mathrm{HCl}$ (Sigma) and incubated for 30 minutes. After this second incubation, the gel was placed in a solution containing $1 \%$ Triton $100 \mathrm{x}, 0.05 \mathrm{M}$ Tris- $\mathrm{HCl}$ and $0.005 \mathrm{M} \mathrm{CaCl}_{2}$ (Sigma) and incubated at $37^{\circ} \mathrm{C}$ for 24 hours. Following this incubation period, the gels were stained with a $0.1 \%$ Brilliant Blue R-250 stain containing 50\% methanol, $40 \%$ distilled water, and $10 \%$ acetic acid. Once stained, the gel was then de-stained in a solution containing $75 \%$ distilled water, $20 \%$ methanol, and $10 \%$ acetic acid. Pre-stained molecular weight markers (Biorad Mississauga, ON) were also resolved on the same gel. The location of the pre-stained markers on the gel was documented prior to the staining of the gel with Brilliant Blue R-250. Gelatinase activity appeared as zones of clearing (due to gelatin degradation) against a blue background. The identity of the MMPs was determined by comparison of the relative positions of the zones of clearing (due to gelatin degradation) with the documented positions on the gel of the molecular weight markers. 
Cytosolic Protein Fraction and Nuclear Protein Fraction Isolation: Protein expression was determined in the whole cytosolic protein fraction. Briefly, the cell pellets were removed from $80^{\circ} \mathrm{C}$ and placed on ice. The pellets were then reconstituted in $100 \mathrm{ul}$ of $10 \mathrm{mM}$ Tris- $\mathrm{HCl}$ buffer $(7.4 \mathrm{pH})$ containing $0.5 \mathrm{mM}$ PMSF (Sigma). Once reconstituted, the cells were then briefly sonicated. The cell lysates were then centrifuged for 10 minutes at $9,300 \mathrm{x} g$ at $4^{\circ} \mathrm{C}$. Following this centrifugation, the supernatant was removed from the pellet and subsequently evaluated. The total protein content of the supernatant was determined by Biorad protein assay (Biorad ) as per the manufacturer's instructions .

This nuclear isolation procedure was essentially as previously described (Wang et al 2009). Briefly, the previously prepared cell samples were removed from $-80^{\circ} \mathrm{C}$ and placed on ice. These cells were then incubated on ice in a buffer containing $10 \mathrm{mM}$ HEPES (pH 7.9), $1.5 \mathrm{mM} \mathrm{MgCl}_{2}$, $10 \mathrm{mM} \mathrm{KCl}, 0.5 \mathrm{mM}$ DTT and $0.5 \mathrm{mM}$ PMSF for 10 minutes. After 10 minutes the cells were centrifuged at $10,000 \mathrm{x}$ g for 10 minutes at $4^{\circ} \mathrm{C}$. Once centrifuged, the supernatant containing the cytosolic proteins was removed from the pellet and stored at $-80^{\circ} \mathrm{C}$. The remaining pellet was then re-suspended in a buffer containing 20mM HEPES, 25\% (v/v) glycerol, $0.42 \mathrm{M} \mathrm{NaCl}$, $1.5 \mathrm{mM} \mathrm{MgCl} 2,0.2 \mathrm{mM}$ EDTA, $0.5 \mathrm{mM}$ DTT and $0.5 \mathrm{mM}$ PMSF. The contents were then incubated on ice for 40 minutes with vigorous shaking. Once 40 minutes had passed, the contents were then centrifuged at $10,000 \mathrm{x}$ g for 15 minutes at $4^{\circ} \mathrm{C}$. After centrifugation the supernatant (containing the nuclear proteins) was removed and stored at $-80^{\circ} \mathrm{C}$ until used. The total protein content of the cytosolic and nuclear fractions was determined by Biorad protein assay.

Immunoblot Analyses: Equal amounts of protein extracts from whole, cytosolic, and nuclear fractions were mixed in a 3:1 ratio with standard Laemmili buffer consisting of $50 \mathrm{mM}$ Tris- $\mathrm{HCl}$ (pH 6.8), 10\% SDS , 0.1\% bromophenol blue, 10\% glycerol and 100mM beta-mercaptoethanol. Once mixed, these samples were boiled for 3 minutes. Once boiled, they were resolved by electrophoresis through 10\% SDS-PAGE gels and were transferred onto nitrocellulose membranes (Biorad) . After transfer, the membranes were incubated in the presence of a $1 \%$ BSA (w/v) TBS-Tween $(0.05 \% \mathrm{v} / \mathrm{v})$ solution for one hour at room temperature. Then, the membranes were incubated with primary antibodies diluted to a 1:200 ratio (v/v). The membranes were incubated in the presence of the primary antibody for 24 hours at $4{ }^{\circ} \mathrm{C}$. After incubation the membranes were then washed three times with TBS-Tween $(0.05 \%)$ for ten minutes and were then incubated in alkaline phosphatase-conjugated secondary antibodies (1:2000 dilution) for 1 hour. After incubation, the membranes were again washed three times with TBS-Tween $(0.05 \%)$ for ten minutes, washed briefly with distilled water, and then exposed SigmaFast BCIP-NBT tablets (Sigma) in solution to visualize protein expression levels. Such Western blots were then analysed using Infinity Capture software (Lumenera Corp., Ottawa, $\mathrm{ON}$ ), and densitometry was performed with ImageJ software (National Institute of Health, Bethesda, MA).

Alamar Blue Cytotoxicity Assay: The Alamar Blue assay was performed to determine cellular viability after treatment with PACs at $25 \mathrm{ug} / \mathrm{ml}$ at 3 and 6 hours of treatment an Alamar Blue assay (Invitrogen, Burlington, $\mathrm{ON}$ ) was performed as per manufacturer's instructions. Briefly, 
DU145 cells were subcultured into a 96 well plate at 5,000 cells/well. After 24 hours of incubation, the media was replaced with $100 \mathrm{ul}$ of serum-free media and was once again incubated for 24 hours. After this incubation, the cells were treated with FL for 6 hours, with a final concentration of DMSO within each well of $0.1 \%$. The control for this experiment was DU145 cells treated with DMSO at a total concentration of $0.1 \%$ for 6 hours. Following treatment, $10 \mathrm{ul}$ of Alamar Blue was added to each well in order to reach a final volume of $10 \%$ Alamar Blue in each well. The cells were incubated for 3 hours post exposure of the cells to Alamar Blue. After this 3 hour incubation period, the resulting fluorescence was read with an excitation wavelength of $528 \mathrm{~nm}$ and an emission wavelength of $590 \mathrm{~nm}$.

\section{RESULTS}

Analysis of the Flavonol-Enriched Fraction (FL): HPLC analysis of flavonoid fractions from cranberry fruit has been previously described [19,22]. Flavonol glycosides (primarily of quercetin) were detected based on characteristic absorbance at $355 \mathrm{~nm}$ and identified by comparison to authentic standards and previous studies [20]. The FL fraction contained 58\% flavonol glycosides by weight. Constituents identified in the FL fraction (as shown in Figure 1) were: myricetin-3-galactoside, myricetin-3-arabinoside, quercetin-3-galactoside, quercetin-3glucoside, quercetin-3-xyloside, quercetin-3-arabinofuranoside, quercetin-3-arabinopyranoside and quercetin-3-rhamnoside, consistent with fractions reported previously [22] as well as minor amounts of procyanidins, B2 and A2. No significant anthocyanin was present in the fraction. The major constituent, approximately $18 \%$ of the fraction, is quercetin-3-galactoside or hyperoside (Figure 1, Peak 6).

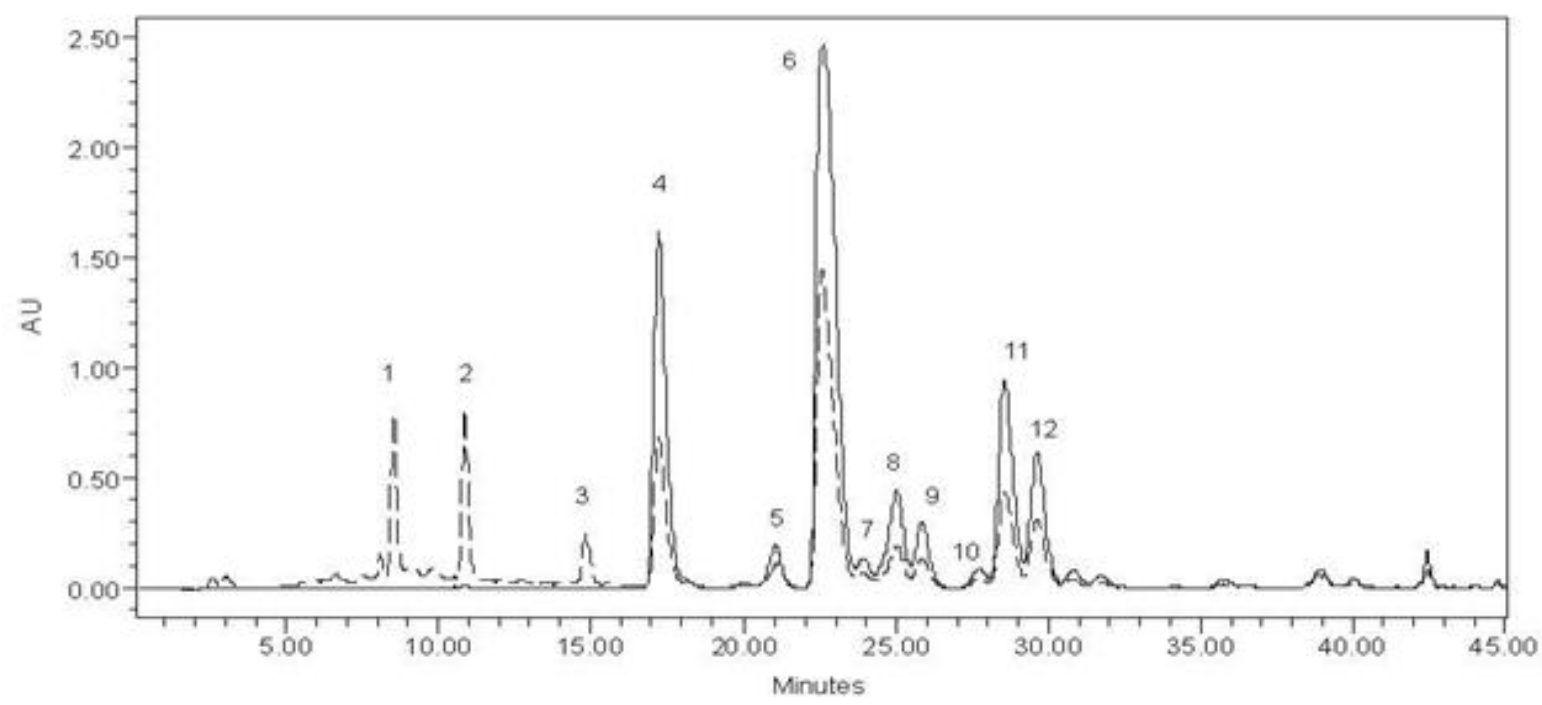

Figure 1: Analysis of the FL enriched fraction. HPLC profile of the FL fraction monitored at $355 \mathrm{~nm}$ (solid line) and $280 \mathrm{~nm}$ (dashed line) is illustrated. The constituents were identified as: (1) procyanidin B2 (2) unknown proanthocyanidin ( 3) procyanidin A2 ( 4) myricetin-3-galactoside (5) myricetin-3-arabinoside (6) quercetin-3-galactoside (7) quercetin-3-glucoside ( 8) quercetin-3-xyloside (9) quercetin-3-arabinofuranoside (10) unknown quercetin derivative (11) quercetin-3-arabinopyranoside and (12) quercetin-3-rhamnopyranoside 
Cranberry FL Decrease DU145 Cell Viability at $25 \mathrm{ug} / \mathrm{ml}$ after 6 Hours: A cytotoxicity assay using Alamar Blue to assess cellular viability in DU145 prostate cancer cells in response to treatment with PACs was performed. As shown in Figure 2, treatment of DU145 cells with FL $(25 \mathrm{ug} / \mathrm{ml}$ ) for 6 hours results in $20 \%$ inhibition of cellular viability. A concentration of FL ( 25 $\mathrm{ug} / \mathrm{ml}$ ) was chosen for further study as this concentration of FL was determined to be the effective concentration which resulted in a substantial effect on the behaviour of DU145 cells which warranted and permitted further investigations.

\section{FL Cytotoxicity Assay}

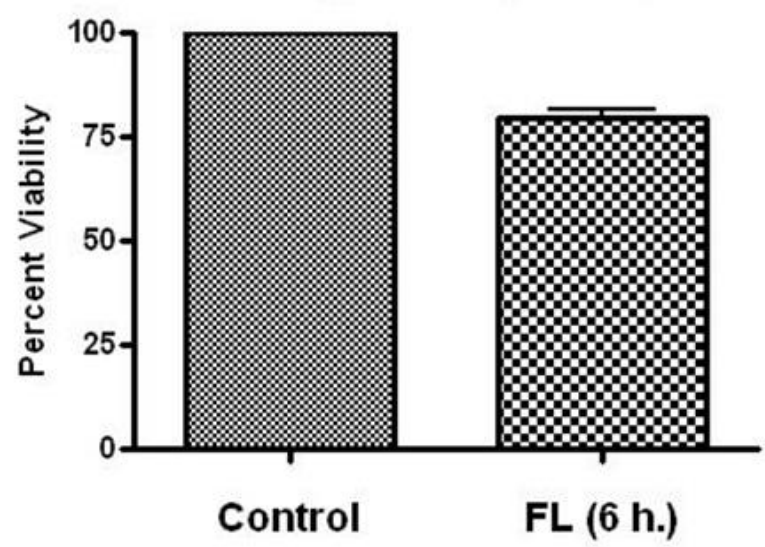

Figure 2: FL Treatment of DU145 Cells Can Affect Cellular Viability. DU145 cell viability was evaluated by Alamar Blue assay following treatment of cells with $25 \mathrm{ug} / \mathrm{ml}$ of FL for 6 hours. Control cells received $0.1 \%$ DMSO (vehicle) alone for 6 hours. Fluorescence was read at 528 excitation and 590 emission wavelengths. Control cells were determined to represent $100 \%$ viability.

Cranberry FL Decreases MMP-2 and MMP-9 Activity in DU145 cells in vitro: To investigate the effects of FL upon MMP activity, gelatin gel electrophoresis was performed with the cell media after treatment with FL $(25 \mathrm{ug} / \mathrm{ml})$ for 6 hours. As shown in Figure 3, MMP-2 and MMP-9 activity decreases after 6-hour treatment with FL. MMP-2 and MMP-9 activities decreased approximately $40 \%$ and $70 \%$, respectively.

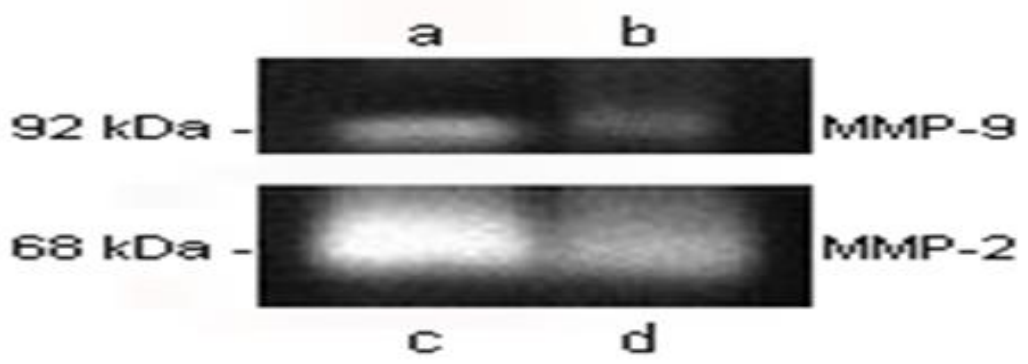

Figure 3: Cranberry FL decreases MMP -2 and MMP-9 activity. Gelatin gel electrophoresis was performed on aliquots of conditioned medium obtained from DU145 cells following exposure to FL. (a) MMP-9 activity in control cells (1 \% DMSO for 6 hours) (b), and in cells exposed to FL ( $25 \mathrm{ug} / \mathrm{ml}$ ) for 6 hours (c) MMP-2 activity in control cells and (d) in cells exposed to FL (25 $\mathrm{ug} / \mathrm{ml}$ ) for 6 hours . 
Cranberry FL Increase the Expression of TIMP-2, an MMP Inhibitor: Having shown that treatment of DU145 cells with FL results in inhibition of both MMP-2 and MMP-9 activities, the effects of FL on the expression of a number of key factors known to regulate the expression of MMP-2/-9 was evaluated. These regulatory factors included the extracellular matrix metalloproteinase inducer (EMMPRIN) and two tissue inhibitors of matrix metalloproteinases (TIMPs), TIMP-1 and TIMP-2 and reversion-inducing-cysteine-rich protein with Kazal motifs ( RECK), an inhibitor of MMP-9. As shown in Figure 4, there was an increase in the protein expression levels of TIMP-2 and EMMPRIN, a decrease in the protein expression levels of TIMP-1 and no readily apparent change in the protein expression levels of RECK after treatment of DU145 cells with cranberry FL ( $25 \mathrm{ug} / \mathrm{ml})$ for 6 hours.

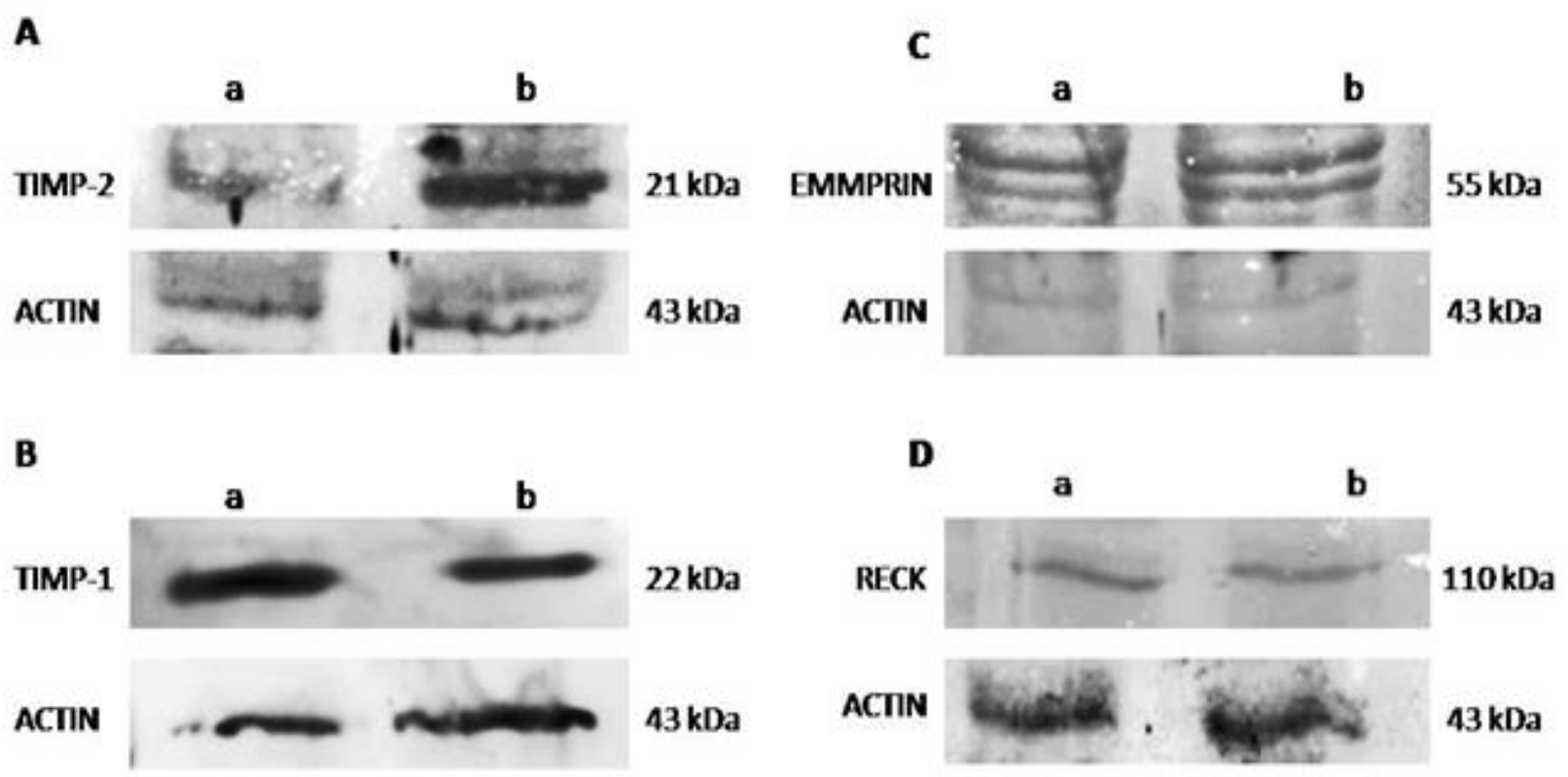

Figure 4: Cranberry FL increases TIMP-2 and EMMPRIN protein expression levels and decreases TIMP-1 protein expression levels with no apparent effect on RECK protein expression in DU145 cells. Vehicle-treated cells are shown in (a) and FL (25 ug/ml)-treated (6-hour ) cells are shown in (b) Actin was used as a loading control.

Cranberry FL affects uPA expression and uPA-associated activities in DU145 cells: To investigate the effects of FL on the UPA system in DU145 cells, the effect of FL on the protein expression levels of uPA was determined. As shown in Figure 5, in response to treatment with FL ( $25 \mathrm{ug} / \mathrm{ml}$ ) for 6 hours, the protein expression levels of uPA markedly decreased, as did the expression of levels of the receptor for uPA namely uPAR. ( Figure 5 ). These decreases in uPA were accompanied by alterations in PAI-1 and PAI-2 protein expression levels (PAI-1 AND PAI-2 are plasminogen activator inhibitors.). The protein expression levels of PAI-1 and PAI-2 were increased and unaltered, respectively in response to treating DU145 cells with FL (25 $\mathrm{ug} / \mathrm{ml}$ ) for 6 hours (Figure 5). 
PAI-1

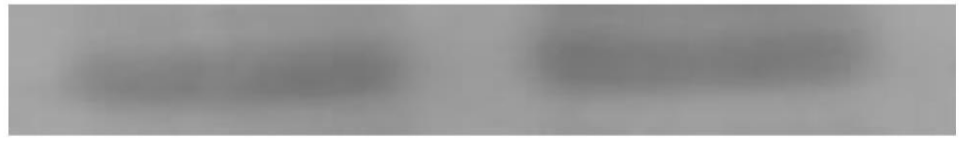

$50 \mathrm{kDa}$

Actin

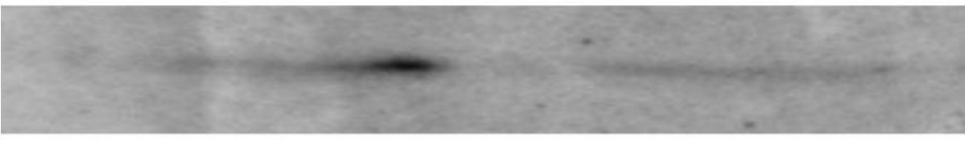

$43 \mathrm{kDa}$

PAI-2

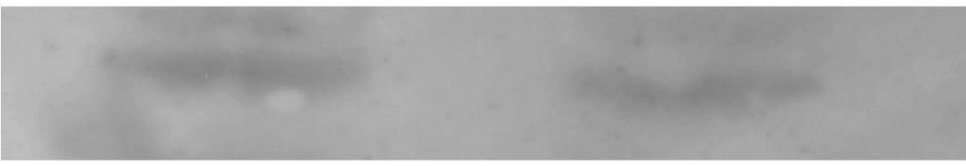

$60 \mathrm{kDa}$

Pro- uPA

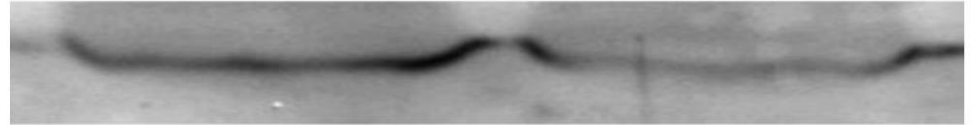

55 kDa

Active- uPA

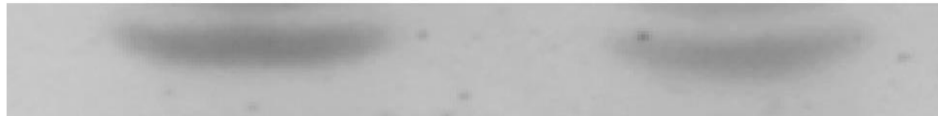

33 kDa

UPAR

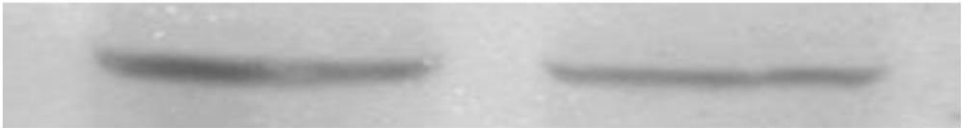

60 kDa

Actin

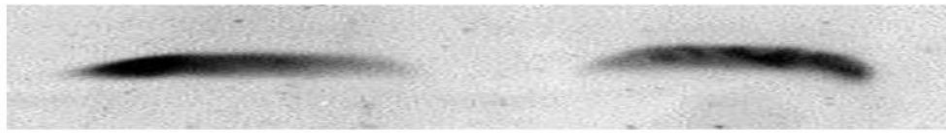

43 kDa

Control

6 Hours

Figure 5. Cranberry FL decreases uPA and affects the expression of related regulatory proteins. The protein expression levels of uPA, uPAR, PAI-1 and PAI-2 in vehicle treated cells and in FL - treated cells are shown. Actin was used as a loading control.

Cranberry FL Affects the Expression of MAPK Pathway Proteins and the Expression of PI3-Kinase Pathway Proteins: To further characterize the mechanisms whereby cranberry flavonols can inhibit MMP-2/-9 expression levels and uPA expression levels, the effects of FL $(25 \mu \mathrm{g} / \mathrm{ml})$ ( 6 hours treatment) on key cellular signal transduction proteins were determined. A number of cellular signalling proteins including those associated with the mitogen activated protein kinase (MAPKs) pathway and the phosphatidylinositol-3 kinase (PI3-kinase) pathway which subsequently activate AP-1 and NF9B have been implicated in the regulation of the expression of MMPs (Lee et al., 2009). Western blot analyses were performed with cell lysates from DU145 cells following 6 hours of treatment with FL $(25 \mathrm{ug} / \mathrm{ml})$ and protein expression levels of a number of proteins evaluated. As shown in Figure 6 , results indicated that after treatment of DU145 cells with FL, the protein expression levels of ERK1 and ERK2 were 
unaffected whereas the protein expression levels of p-ERK, p-p38 and JNK-2 decreased and the protein expression levels of JNK-1, p-JNK-1, p-JNK-2 and p38 were all increased. (Figure 6).

A

p-ERK

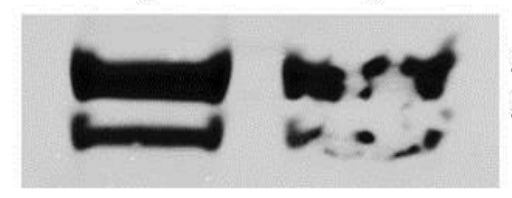

ERK 1

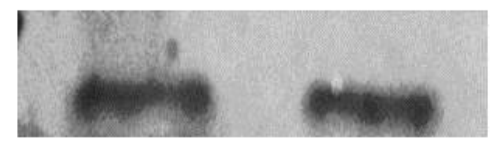

ERK 2

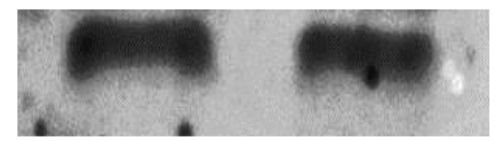

$44 \mathrm{kDa}$

$42 \mathrm{kDa}$

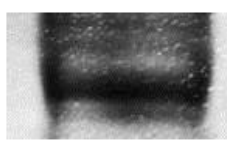

$42 \mathrm{kDa}$

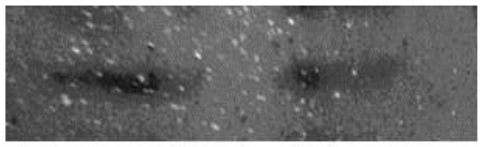

$53 \mathrm{kDa}$

JNK-2

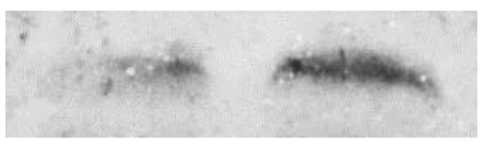

ACTIN

JNK-1

$46 \mathrm{kDa}$

$43 \mathrm{kDa}$
B

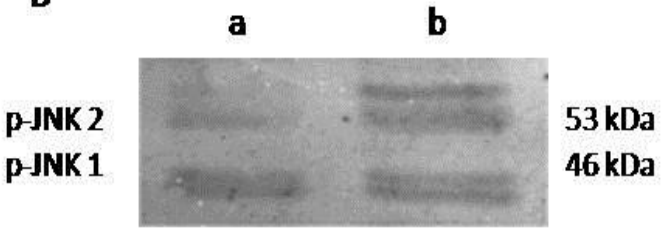

p38

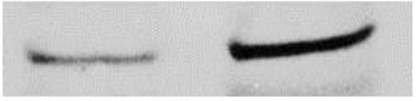

$38 \mathrm{kDa}$

ACTIN

$43 \mathrm{kDa}$

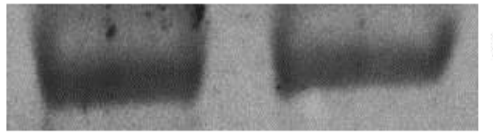

Figure 6: Cranberry FL affects the expression of proteins associated with the MAPK kinase pathway. A: p-ERK, ERK-1, ERK-2, p-p38, JNK- 1 and JNK-2 and actin protein expression levels, respectively, are shown in vehicle-treated cells (a) and in FL ( $25 \mathrm{ug} / \mathrm{ml}$ ) ( for 6 hours) treated cells (b). Actin was used as a loading control. B: p-JNK-1, p-JNK-2, p38 and actin

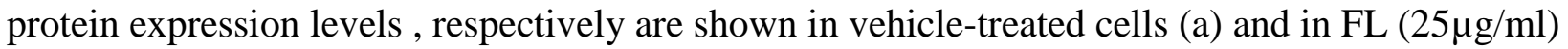
(for 6 hours) treated cells (b).

To further investigate the nature of the cellular signalling proteins involved in the cranberry flavonols-mediated inhibition of MMP-2 /-9 and uPA, the expression of proteins in the PI-3 kinase pathway was evaluated. As such, Western blot analyses were performed and Akt (a protein in the PI-3 kinase pathway) protein levels were determined. As shown in Figure 7 FL treatment of DU145 cells resulted in no apparent change in Akt protein expression with decrease in protein expression levels of p-Akt . To further investigate the mechanisms by which FL act Western blot analyses were performed to examine the expression of PI-3 kinases (p85 and p110 proteins). The expression of both PI-3 kinase p85 and PI-3 kinase p110 protein levels decreased and increased respectively in DU145 cells in response to treatment of these cells with FL (Figure 7). 
A

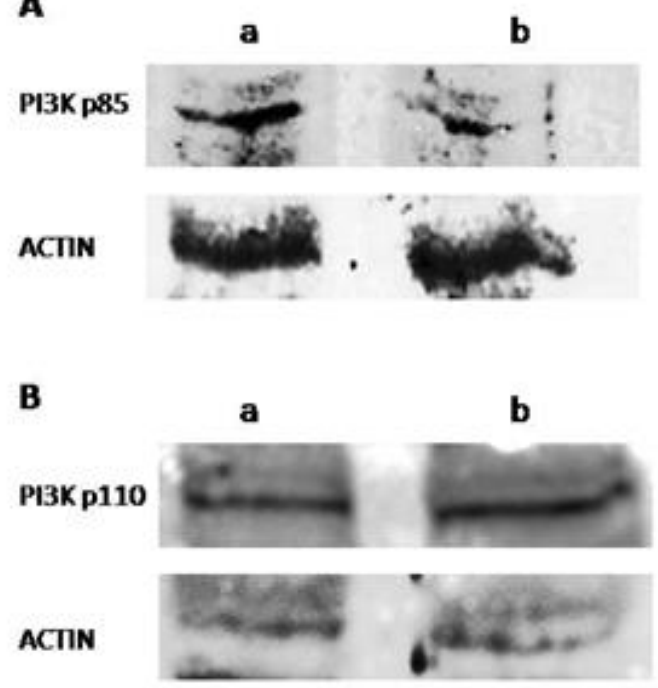

C

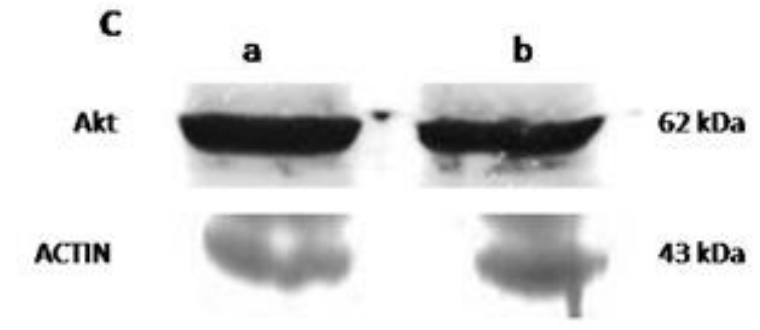

$110 \mathrm{kDa}$

$43 \mathrm{kDa}$

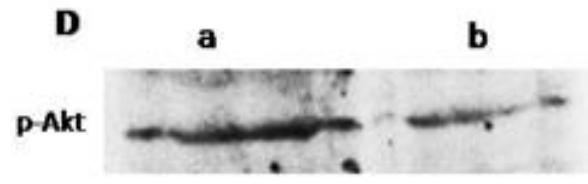

$70 \mathrm{kDa}$

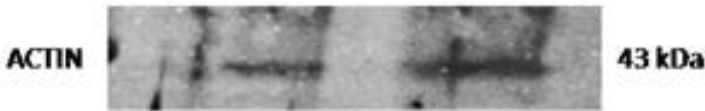

Figure 7: Cranberry FL affects the expression of PI-3 kinase pathway proteins. A: Western blot analysis of PI-3K p85, and actin protein expression levels in vehicle-treated cells (a) and in FL ( $25 \mathrm{ug} / \mathrm{ml}$ )-treated ( for 6 hours ) cells (b) B:Western blot analysis of PI3Kp110 and actin protein expression levels are shown as described above. C: Western blot analysis of Akt, and actin protein expression levels in cells as described above. D: Western blot analysis of p-Akt and actin protein expression levels as described above. Actin was used as a loading control.

Cranberry FL affects the expression of proteins associated with the NFkB and AP1 Signaling Pathways: The pathways which can affect the expression of MMPs in cells can activate both AP-1 and NFאB mediated events[23]. Since the expression of MMPs can be affected by the NFאB pathway, NF9B has been suggested to be a pivotal transcription factor in prostate cancer metastasis to bone [24]. The possibility that FL may be also acting via this pathway to affect MMPs and uPA signalling system in DU145 cells was investigated. To determine the amount of NF9B (p65) protein in the nucleus, Western blot analyses were performed with nuclear extracts from untreated DU145 cells and from DU145 cells treated with FL $(25 \mathrm{ug} / \mathrm{ml})$ for 6 hours. To verify the integrity of the nuclear fraction extract prepared, the expression of a nuclear protein, $\mathrm{H} 2 \mathrm{~B}$, which is a core histone protein was evaluated. Results indicated that there was a marked expression of $\mathrm{H} 2 \mathrm{~B}$ protein in the isolated nuclear fraction preparation and none detected in the cytosolic fraction, which was also prepared. This result as shown in Figure 8 suggests that there is an enrichment of this protein in this fraction verifying the successful preparation of a nuclear fraction. Post confirmation of the fidelity of the nuclear fraction prepared, the expression of NF9B pathway proteins was evaluated. As shown in Figure 8 , it was observed that there were alterations in the expression levels of NF9B (p65) protein levels after treatment with PACs. Interestingly, in response to $\mathrm{FL}, \mathrm{NFKB}(\mathrm{p} 65)$ protein expression levels increased in the nucleus with no readily apparent change of NFKB (p65) protein expression levels in the cytoplasm ( Figure 8). This suggests that the nuclear protein levels were not a result of decreases in p65 protein translocation. In order to further investigate the effects of FL on NFкB- pathway associated proteins, Western blot analyses were performed and the 
protein expression levels of $\mathrm{I} 9 \mathrm{~B} \alpha$, and $\mathrm{p}-\mathrm{IKB} \alpha$ were determined. As shown in Figure 8, results indicated that no change in the amount of $\mathrm{I9B} \alpha$ occurred in response to FL treatment whereas the protein expression levels of $\mathrm{p}-\mathrm{IkB} \alpha$ markedly increased. . Additionally, as shown in Figure 8, it was observed that FL treatment of DU145 cells resulted in increased expression of c-jun protein and increased expression of c-fos protein.

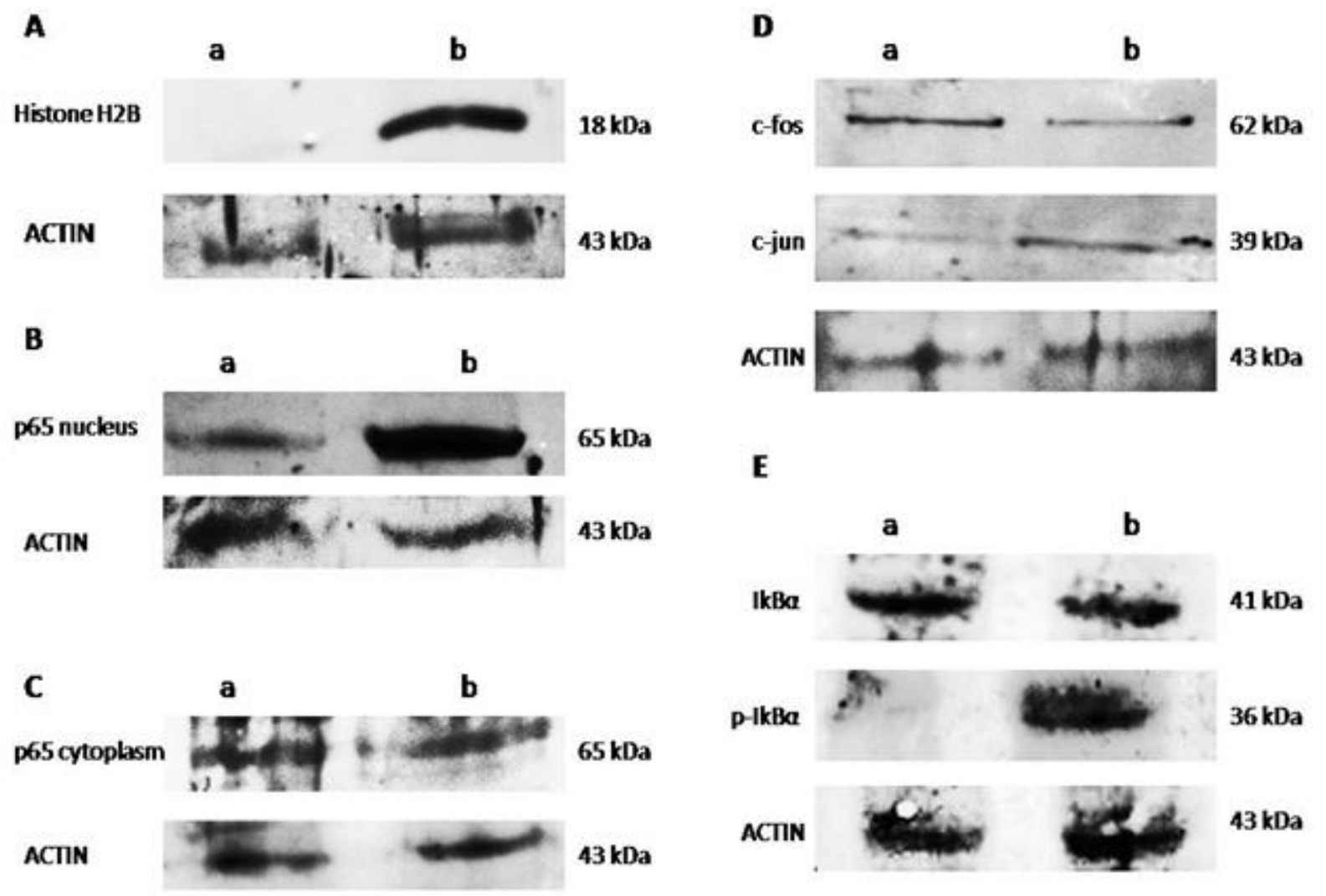

Figure 8: Cranberry FL affect protein expression levels of proteins in the NK9B pathway and AP1 pathways. A: Western blot analysis of histone $\mathrm{H} 2 \mathrm{~B}$ protein expression levels in the cytosolic fraction (a) and in the nuclear fraction (b) from DU145 cells treated with $25 \mathrm{ug} / \mathrm{ml}$ of FL for 6 hours. Nuclear-enriched cell lysates and cytosolic cell lysates (10 ug of protein each) were electrophoresed through a 10\% SDS-PAGE gel and immunoblotted with anti-histone H2B. Actin was used as the loading control. B: Western blot analysis of p65 and actin protein expression levels in the nuclear enriched cell lysate isolated from vehicle treated control cells (a) and isolated from DU145 cells treated with $25 \mathrm{ug} / \mathrm{ml} \mathrm{FL} \mathrm{for} 6$ hours (b). Actin was used as a loading control. C: Western blot analysis of p65 protein expression levels in the cytosolic cell lysate isolated from vehicle treated control cells (a) and isolated from cells treated with $25 \Phi \mathrm{g} / \mathrm{ml}$ FL for 6 hours (b). Actin was used as a loading control. D: Western blot analysis of c-fos, c-jun, and actin protein expression level in nuclear cell lysates isolated from vehicle treated control cells (a) and isolated from cells treated with $25 \mathrm{ug} / \mathrm{ml}$ of FL for 6 hours. Actin was used as a loading control. E: Western blot analysis of $\mathrm{I} 9 \mathrm{~B} \alpha$ and $\mathrm{pI} 9 \mathrm{~B} \alpha$ protein expression levels in cell lysates isolated from vehicle treated control cells (a) and isolated from DU145 cells treated with $25 \mathrm{ug} / \mathrm{ml}$ of FL for 6 hours (b). Actin was used as a loading control. 


\section{DISCUSSION:}

In this study we examined the effects of cranberry FL upon MMP activity and uPA activity in DU145 human prostate cancer cells in vitro.. Cranberry FL was able to inhibit MMP-2 and MMP-9 activity and uPA activity and this inhibition was part of the cytotoxic response associated with FL treatment of DU145 cells, which was observed post 6 hours of treatment.

Different flavonoids and their effects upon MMP activity have been recently examined and these studies have suggested that they limit the activity of MMPs [25]. Quercetin has been shown to down-regulate matrix metalloproteinases 2 and 9 protein expression in PC3 prostate cancer cells [26] and this study suggested that the inhibition of metastasis-associated MMPs in cancer cells may be one of the targets for the anticancer function of quercetin [26]. These findings are in agreement with the current study performed using DU145 human androgen insensitive prostate cancer cells which also showed inhibition of MMPs ( and also uPA) in response to cranberry FL. Moreover this study provides a detailed analysis of the possible regulatory mechanisms involved. The decrease in MMP activity and uPA activity seen in response to cranberry FL treatment occurs in a multi-factorial manner affecting key regulatory activities of both MMPs and urokinase. This occurs by the modulation of expression of a number of key proteins associated with the MAP kinase, PI3 kinase, NFKB and AP-1 cellular signalling pathways. In this regard, quercetin has been previously observed to inhibit the expression and activity of matrix metalloproteinases ( MMP-2 and MMP-9) and to reduce the protein expression levels of urokinase-type plasminogen activator ( UPA) in SAS human oral cancer cells [27]. These effects were associated with the inhibition of the migration and invasion of these cells [27]. Quercetin was determined to do this via a down-regulation of protein kinase C and RhoA protein by blocking MAP kinase and PI3 kinase / AKT signalling pathways and NFKB and uPA signalling which resulted in the inhibition of MMP-2 and MMP-9 signalling [27]. These findings are consistent with our findings which illustrated alterations in the uPA signalling system associated with alterations in the MAP kinase, PI3 kinase, NFKB ( and AP-1) signalling systems when cells are exposed to cranberry flavonols.

In summary, this study has demonstrated and characterized a novel relationship between cranberry flavonol-enriched fraction isolated from Vaccinium macrocarpon (American cranberry) and the expression and regulation of matrix metalloproteinases ( specifically MMP-2 and MMP-9) and urokinase in DU145 human prostate cancer cells. Our previous studies have shown that a whole cranberry extract and a proanthocyanidin -enriched fraction (PACs) are capable of affecting the expression of MMPs in DU145 cells $[17,18]$. This study has extended our previous observations and has further identified the specific nature of further compounds from cranberry that may be responsible for cranberry's effects on MMPs, as well as, the urokinase signalling system.

\section{CONCLUSIONS:}

In conclusion, the present study has shown that flavonols isolated from American cranberry (Vaccinium macrocarpon) can affect the expression of MMPs and uPA and their associated regulatory systems and further elucidated the cellular signalling pathways affected. This present study also contributes to our understanding of how commonly used botanicals and natural products are capable of regulating the behaviour of prostate cancer cells and as such provides 
continued support of the potential health benefits of "bioactive" phytochemicals present in the American cranberry (Vaccinium macrocarpon) toward better prostate health.

Abbreviations: AP-1: activator protein-1, BSA: bovine serum albumin, DTT: dithiothreitol, DMSO: dimethyl sulfoxide, ECM: extracellular matrix, EMMPRIN: extracellular matrix metalloproteinase inducer, ERK: extracellular signal regulated kinase, FL: flavonol-enriched fraction, HPLC: high performance liquid chromatography, $\mathrm{IKB} \alpha$ : NK kappaB inhibitor alpha, JNK: c-Jun -N-terminal kinase, MMP: matrix metalloproteinase, MEM: minimal essential media, MAPK: mitogen-activated protein kinase, $\mathrm{NKK}_{\mathrm{KB}}$ : nuclear factor of kappa light chain enhancer of activated B cells, PMSF: phenylmethanesulfonylfluoride, PAI-1: plasminogen activator inhibitor-1, PAI-2: plasminogen activator inhibitor-2, SDS: sodium dodecyl sulphate, SDS-PAGE: sodium dodecyl sulphate polyacrylamide gel electrophoresis, RECK: reversioninducing-cysteine-rich protein with Kazal motifs, TIMP-1: tissue inhibitor of matrix metalloproteinase-1, TIMP-2: tissue inhibitor of matrix metalloproteinase-2, uPA: urokinasetype plasminogen activator, uPAR: urokinase-type plasminogen activator receptor.

Competing Interests: The authors have no competing interests to declare.

Author's Contributions: J. MacPhee, (Directed Studies in Research student [ Hurta lab]), B. Elwood, (Honours in Biology Research Student [ Hurta lab]) and C. Stetson (a graduate student ([Hurta and McCallum labs]) performed the research described in this manuscript and also edited the manuscript. K. Patel (graduate student in Neto lab) was responsible for the preparation and characterization of the flavonol fraction used in this study. C. Neto and J. McCallum are cosenior investigators associated with this work and were responsible for editing the manuscript and for acquisition of grant funding required to undertake this project and support the students performing the studies. R. Hurta is the primary senior investigator associated with this work and was responsible for the supervision of the research described, drafting and editing the manuscript and was also responsible for acquisition of grant funding required to undertake this project and support students performing the studies.

Acknowledgments: This work was supported by funding (research grant) from the Cranberry Institute [Wisconsin Board], the Canadian Cancer Society, the P.E.I Health Research Program, and the Jeanne and J.-Louis Levesque Foundation. C. Stetson is supported by funds from Agriculture and Agri-Food Canada, A-base, Project 1268.

\section{REFERENCES:}

1. Yousif R, Herzog M, Che M, Upadhyay J, Shekarriz B, Shekarriz B, Bhagat S, Mullins C, Fridman R, Cher M. 2002. Matrix metalloproteinase activity, bone matrix turnover, and tumor cell proliferation in prostate cancer bone metastasis. Journal of the National Cancer Institute 94:17-25.

2. Gimeno-Garcíaa AZ, Santana-Rodrígueza A, Jiménez A, Parra-Blanco A, NicolásPérez D, Paz-Cabrera C, Díaz-González F, Medina C, Díaz-Flores L, Quintero E. 2006. 
Up-regulation of gelatinases in the colorectal adenoma-carcinoma sequence . European Journal of Cancer 42:3246-3252.

3. Bachmeier BE, Nerlich AG, Lichtinghagen R, Summerhoff CP 2001. Matrix metalloproteinases (MMPs) in breast cancer cell lines of different tumorigenicity. Anticancer Research 21:3821-3828.

4. Björklund M, Koivunen, E. 2005. Gelatinase-mediated migration and invasion of cancer cells. Biochimica et Biophysica Acta 1755:37-69.

5. Senthilkumar, K. Arunkumar, R., Elumalai, P., Sharmila, G., Gunadharini, D., Banudevi, S., Krishnamoothy, G., Benson, C. Arunakaran, J., 2011. Quercetin inhibits invasion, migration and signalling molecules involved in cell survival and proliferation of prostate cancer cell line (PC3), Cell Biochem. Function, 29,87-95.

6. 6.Andreasen, P., Kjoller,L., Christensen, L., Duffy, M., 1997. The urokinase-type plasminogen activator system in cancer metastasis: a review. Int. J. Cancer, 72,1-22

7. Fuhrman, B., 2012. The urokinase system in the pathogenesis of atherosclerosis. Atherosclerosis. 222, 8-14.

8. Roomi, M., Karlinovsky, T., Rath, M., Niedzwiecki, A. 2011. Down-regulation of urokinase plasminogen activator and matrix metalloproteinases and up-regulation of their inhibitors by a novel nutrient mixture in human prostate cancer cell lines PC-3 and DU-145. Oncol. Rep. 26,1407-1413.

9. Cohen JH, Kristal AR, Stanford JL 2000. Fruit and Vegetable Intakes and Prostate Cancer Risk. Journal of the National Cancer Institute 92:61-68.

10. 10.Steinmetz, K.A., Potter,J.D., 1991. Vegetables, fruits and cancer. Mechanisms. Cancer Causes and Controls , 2, 427-442.

11. Neto C. 2007.Cranberry and its phytochemicals: a review of in vitro anticancer studies. The Journal of Nutrition 137:186-193.

12. Pan M, Ghai G, Ho C. 2008. Food bioactives, apoptosis, and cancer. Molecular Nutritional Food Research 52:43-52.

13. Gallo D, Zannoni GZ, Stefano ID, Mosca M, Ferlini C, Mantuano E, Scambia G. 2008. Soy phytochemicals decrease nonsmall cell lung cancer growth in female athymic mice. The Journal of Nutrition 138:1360-1364.

14. Liu E, Wu J, Cao W, Zhang J, Liu W, Jiang X, Zhang X. 2007. Curcumin induces G2/M cell cycle arrest in a p53-dependent manner and upregulates ING4 expression in human glioma. Journal of Neuro-Oncology 85:263-270.

15. Deziel, B.A., MacPhee, J., Patel, K.,Catalli, A., Kulka, M., Neto, C., Gottschall-Pass, K., Hurta, R.A.R., (2012) American cranberry ( Vaccinium macrocarpon) extract affects human prostate cancer growth via cell cycle arrest by modulating expression of cell cycle regulators, Food Funct. , 3, 556-564.

16. Vidlar, A., 2010. The effectiveness of dried cranberries (Vaccinium macrocarpon) in men with lower urinary tract symptoms. British J. Nutrition, 104,1181-1189.

17. Deziel, B. Patel, K., Neto, C., Gottschall-Pass, K. Hurta, R., 2010. Proanthocyanidins from the American cranberry (Vaccinium macrocarpon) inhibit matrix metalloproteinase-2 and matrix metalloproteinase -9 activity in human prostate cancer 
cells via alterations in multiple cellular signalling pathways. J. Cell. Biochem., 111,742754.

18. MacLean, M.A., Matchett, M.D., Amoroso, J. , Neto,C., Hurta, R. 2007. Cranberry ( Vaccinium macrocarpon) flavonoids inhibit matrix metalloproteinases (MMPs) in human prostate cancer cells. FASEB J. 21:791.5

19. Patel, K.D., Scarano, F.J., Kondo, M., Hurta, R.A.R., Neto, C., 2011. Proanthocyanidinrich extracts from cranberry fruit (Vaccinum macrcarpon Ait.) selectively inhibit the growth of human pathogenic fungi Candida spp. and Cryptococcus neoformans, J. Agric. Food Chem., 59,24,12864-12873.

20. Yan, X., Murphy,, ,B.T.,, Hammond,G.B., Vinson, J.A., Neto, C., 2002. Antioxidant activities and antitumor screening of extracts from cranberry fruit ( Vaccinium macrocarpon), J. Agric.Food Chem., 50, 5844-5649.

21. Vvedenskaya,I.O., Rosen, R.T., Guido, J.E., Russell, D.J., Mills, K.A., Vorsa, N., 2004. Characaterization of flavonols in cranberry (Vaccinium macrocarpon) powder, J.Agric. Food Chem., 52,188-195.

22. 22. MacLean, M.A., Scott, B.A., Deziel, B., Nunnelley,M., Liberty, A., Gottschall-Pass, K., Neto, C., Hurta, R., 2011. North American cranberry (Vaccinium macrocarpon) stimulates apoptotic pathways in DU145 human prostate cancer cells in vitro, Nutri. Cancer, 63,1, 109-120.

23. Lee Y-S, Tran H., Ta, QV., 2009. Regulation of expression of matrix metalloproteinase9 by JNK in RAW264.7 cells : presence of inhibitory factor(s) suppressing MMP-9 induction in serum and conditioned media. Expt. Mol. Med. 41:4, 259-268.

24. Andela VB, Gordon AH, Zotalis G, Goater JJ, Lewis GD, Schwarz EM, Puzas JE , $\mathrm{O}=$ Keefe RJ, 2003. NFkappaB: a pivotal transcription factor in prostate cancer metastasis to bone. Clin Orthop Relat Res 415(supplement):S75-85.

25. Ende C, Gebhardt R. 2004. Inhibition of matrix metalloproteinase- 2 and -9 activities by selected flavonoids. Planta Medica 70:1006-1008.

26. Vijayababu, M.R., Arunkumar, A., Kanagaraj, P., Venkataraman, P., Krishnamoothy, G., Arunkumar, J., 2006. Quercetin downregulates matrix metalloproteinases 2 and 9 proteins expression in prostate cancer cells (PC3), Mol. Cell. Biochem., 287, 1-2, 109116.

27. Lai, W.W., Hsu, S.C., Chueh, F.S., Chen, Y.Y., Yang, J.S., Lin, J.P., Lien, J.C., Tsai, C.H., Chung., J.G. 2013. Quercetin inhibits migration and invasion of SAS human oral cancer cells through inhibition of NFK-B and matrix metalloproteinase-2/-9 signaling pathways. Anticancer Res., 33, 5, 1941-1950. 